\title{
Estaquia caulinar de guaçatonga (Casearia sylvestris Swartz) nas quatro estações do ano, com aplicação de diferentes concentrações de AlB
}

\author{
SPANDRE, P. ${ }^{1 *}$; ZANETTE, F. ${ }^{2}$; BIASI, L.A. ${ }^{2}$; KOHELER, H.S. ${ }^{2}$; NIESING, P.C. ${ }^{1}$ \\ ${ }^{1}$ Pós-graduação em Agronomia - Produção Vegetal, (UFPR), Rua dos Funcionários, 1540, CEP: 80035-050, Curitiba- \\ Brasil *pspandre@ufpr.br ${ }^{2}$ Departamento de Fitotecnia e Fitossanitarismo da UFPR, Rua dos Funcionários, \\ 1540, CEP: 80035-050, Curitiba-Brasil
}

\begin{abstract}
RESUMO: Casearia sylvestris Swartz (Salicaceae) ou guaçatonga é uma árvore nativa do México, da América Central, e da América do Sul, com grande importância ecológica, farmacológica, e comercial. No entanto, como a maioria das espécies nativas de interesse medicinal no Brasil, a guaçatonga não é cultivada comercialmente, sendo obtida por extrativismo. O presente trabalho foi conduzido com o objetivo de testar um protocolo de propagação vegetativa de guaçatonga por meio da estaquia, visando identificar qual a melhor estação do ano para o enraizamento de estacas e avaliar o efeito da utilização do regulador vegetal ácido indolbutírico (AIB). No outono, inverno e primavera de 2007, e no verão de 2008, estacas caulinares semilenhosas de $12-14 \mathrm{~cm}$ de comprimento e com duas folhas foram preparadas e tratadas com $\operatorname{AIB}(0,1000,2000$ e 3000 $\mathrm{mg} \mathrm{L}^{-1}$ ), em solução alcoólica, através da imersão rápida por 10 segundos da base das estacas, e foram plantadas em tubetes contendo substrato Plantmax $\mathrm{HT}^{\circledR}$ em casa-de-vegetação sob nebulização intermitente. $O$ delineamento experimental utilizado foi o inteiramente casualizado, com 4 repetições, 4 tratamentos, e 16 estacas por parcela. Todos os experimentos foram avaliados após 90 dias, sendo que para dois deles (primavera 2007 e verão 2008) prolongou-se o tempo de permanência em casa-de-vegetação para melhor desenvolvimento das raízes. Foram avaliados os parâmetros: porcentagem de estacas enraizadas, porcentagem de estacas vivas (com calos e sem raízes, sem calos e sem raízes), porcentagem de folhas retidas, porcentagem de estacas mortas, número de raízes, comprimento das três maiores raízes $(\mathrm{cm})$, e média da massa seca das raízes (mg). Não ocorreu enraizamento nas estacas retiradas no outono e no inverno. Com as estacas retiradas na primavera obteve-se $39,1 \%$ de enraizamento. Estacas coletadas no verão não responderam como o esperado, apresentando, após 240 dias, $6,3 \%$ de enraizamento no tratamento com $3000 \mathrm{mg} \mathrm{L}^{-1}$ de AIB. O AIB até $3000 \mathrm{mg} \mathrm{L}^{-1}$ não estimulou o enraizamento de estacas de guaçatonga e a melhor estação do ano para a estaquia é a primavera.
\end{abstract}

Palavras-chave: Casearia sylvestris Swartz, enraizamento, auxina, sazonalidade

ABSTRACT: Stem cuttings of "guaçatonga" (Casearia sylvestris Swartz) in the four seasons of the year with the use of different IBA concentrations. Casearia sylvestris Swartz (Salicaceae), or "guaçatonga", is a tree native to Mexico and Central and South America, with great ecological, pharmacological and commercial relevance. Similarly to most native species of medicinal interest in Brazil, "guaçatonga" is not commercially cultivated and is obtained by means of extraction. The aim of this study was to test a protocol for the vegetative propagation of "guaçatonga" by means of stem cutting, identifying the best season for stem rooting and assessing the effect of using the growth regulator indolebutyric acid (IBA). In the fall, winter and spring 2007 and summer 2008, semi-hardwood cuttings with 12-14 cm length and two leaves were prepared and treated with IBA $\left(0,1000,2000\right.$ and $\left.3000 \mathrm{mg} \mathrm{L}^{-1}\right)$, in alcohol solution, by rapidly immersing for 10 seconds the base of cuttings and planting them in tubes containing Plantmax $\mathrm{HT}^{\circledR}$ in greenhouse under intermittent nebulization. Experimental design was completely randomized with 4 replicates, 4 treatments and 16 cuttings per plot. All experiments were evaluated after 90 days, and for two of them the time of maintenance in greenhouse was prolonged in order to improve root development. The following parameters were evaluated: percentage of rooted cuttings, percentage of live cuttings (with callus and without roots, without callus and without roots), percentage of retained leaves, percentage of dead cuttings, number of roots, length of the largest roots $(\mathrm{cm})$ and mean dry mass

Recebido para publicação em 24/10/2010

Aceito para publicação em 06/04/2011

Rev. Bras. PI. Med., Botucatu, v.14, n.3, p.529-536, 2012. 
of roots $(\mathrm{mg})$. There was no rooting on cuttings collected during the fall and the winter. For cuttings collected in the spring, $39.1 \%$ rooting was obtained. Cuttings collected in the summer did not show the expected results, presenting after 240 days $6.3 \%$ rooting when treated with 3000 $\mathrm{mg} \mathrm{L}^{-1}$ IBA. Up to $3000 \mathrm{mg} \mathrm{L}^{-1}$, IBA did not stimulate the rooting of "guaçatonga" cuttings and the best season for cutting is spring.

Key words: Casearia sylvestris Swartz, rooting, auxin, seasonality

\section{INTRODUÇÃO}

Casearia sylvestris Swartz ou guaçatonga é uma árvore cuja altura varia entre três e $18 \mathrm{~m}$, com folhas persistentes e inflorescências fasciculadas multifloras (Marquete \& Vaz, 2007). Tradicionalmente associada à família das Flacourtiaceae (Joly, 1998), foi recentemente classificada como pertencente à Salicaceae (APG II, 2003). Difundida amplamente no México, América Central e na maioria dos países da América do Sul, é conhecida no Brasil por diversos nomes populares, tais como cafezinho-do-mato, erva-delagarto e café-bravo (Torres \& Yamamoto, 1986; Marquete \& Vaz, 2007). Ocorre em todos os Estados brasileiros e na maioria dos ambientes florestais, sendo espécie de alta densidade e ampla distribuição, especialmente em matas ciliares (Sleumer, 1980; Lorenzi, 1992; Durigan et al., 2003; Marquete \& Vaz, 2007).

A guaçatonga é popularmente utilizada na fitoterapia brasileira pelas propriedades antiofídicas, antiinflamatórias, cicatrizantes, antivirais e antireumáticas (Borges et al., 2000, 2001; Taylor, 2002; Esteves et al., 2005). Nos últimos anos, a Casearia sylvestris tem sido citada como espécie interessante do ponto de vista farmacológico pela atividade antitumoral (Silva et al., 2008) e antiulcerogênica (Ruppelt et al., 1991).

Não obstante a evidente importância farmacológica e comercial da guaçatonga, como a maioria das espécies nativas de interesse medicinal do Brasil, esta não é cultivada, sendo obtida por extrativismo (Silva, 2003). A guaçatonga propaga-se naturalmente por sementes, mas estudos recentes demonstraram que a propagação vegetativa também é viável (Pereira et al., 2003; Imatomi, 2007; Cavallari, 2008), podendo auxiliar em programas de reflorestamento e plantio de pomares clonais.

A ausência de protocolo exato sobre a propagação vegetativa da guaçatonga compromete tanto as pesquisas de melhoramento genético e produção de mudas, quanto o aperfeiçoamento das técnicas de coleta e a exploração industrial da espécie. Segundo Cavallari (2008), a propagação vegetativa por estacas caulinares minimizaria a pressão extrativista, possibilitando o cultivo em larga escala.

O presente trabalho foi conduzido visando identificar qual a melhor estação do ano para a coleta das estacas para o enraizamento da guaçatonga, bem como avaliar o efeito da aplicação de diferentes concentrações do regulador vegetal ácido indolbutírico (AIB).

\section{MATERIALE MÉTODO}

Os experimentos foram conduzidos em casa-de-vegetação do Departamento de Fitotecnia e Fitossanitarismo da UFPR, em Curitiba - PR. O material de propagação foi coletado de 7 exemplares adultos localizados nos bosques do Campus II Jardim Botânico da UFPR em Curitiba, PR. As coordenadas geográficas centrais aproximadas da área de coleta são latitude $25^{\circ} 44^{\prime} 73,82^{\prime \prime}$ S e longitude $49^{\circ} 23^{\prime} 86,41^{\prime \prime} \mathrm{O}$, com altitude de $930 \mathrm{~m}$. Amostras das plantas matrizes foram identificadas pelo Prof. Dr. Armando Carlos Cervi, do Departamento de Botânica da UFPR e a exsicata dos exemplares utilizados ( $n$ - 359149) foi depositada no Herbário do Museu Botânico Municipal de Curitiba (PR).

Os experimentos realizados nos anos de 2007 e 2008 foram implantados em quatro estações, sendo no final do outono (29/05/07), final do inverno (4/09/ 2007), final da primavera (1/12/2007) e final do verão (4/ 03/2008). Os ramos foram coletados e colocados em baldes com água para evitar a desidratação, sendo efetuados dois cortes, horizontal na extremidade superior e em bisel na base, próximo à gema.

As estacas utilizadas em todas as estações do ano tinham consistência semilenhosa, gemas, e foram retiradas das porções mais jovens de cada ramo, entre o terceiro e o décimo nó, eliminando a parte apical dos mesmos. Foram mantidas duas folhas inteiras em cada estaca e todas possuíam entre 5 e 6 gemas, aproximadamente, dependendo do comprimento dos entrenós. O tamanho das estacas variou entre 12 e 14 $\mathrm{cm}$ e o diâmetro médio, mensurado com paquímetro digital na região mediana da estaca, foi de $0,2-0,3 \mathrm{~cm}$. A base das estacas, aproximadamente a $3 \mathrm{~cm}$, foi imersa nas soluções de AIB por 10 segundos, constituindo tratamento de imersão rápida.

O preparo das soluções de AIB foi realizado diluindo-se o regulador na forma de pó em $25 \mathrm{~mL}$ de álcool etílico comum (98 GL), completando com água destilada até o volume final $(50 \mathrm{~mL})$. Foram testadas, em cada estação do ano, quatro concentrações de AIB de 1000,2000 e $3000 \mathrm{mg} \mathrm{L}^{-1}$ e uma testemunha (solução hidroalcoólica 50\%). Após a aplicação do AIB as estacas foram plantadas em tubetes de polipropileno com capacidade de $53 \mathrm{~cm}^{3}$, contendo substrato Plantmax $\mathrm{HT}^{\circledR}$. As bandejas contendo os tubetes com as estacas foram colocadas para enraizar em casa de

Rev. Bras. PI. Med., Botucatu, v.14, n.3, p.529-536, 2012. 
vegetação sob nebulização intermitente (das 8:00 às 17:00 h com irrigação de $15 \mathrm{~s}$ a cada $15 \mathrm{~min}$; das $17: 00$ às $23: 00 \mathrm{~h}$ com irrigação de $15 \mathrm{~s}$ a cada 1 hora; e das 23:00 às 8:00 h irrigação de $15 \mathrm{~s}$ a cada $3 \mathrm{~h}$ ) em todas as estações do ano.

Após 90 dias da instalação, foram avaliadas em todos os experimentos a porcentagem de estacas enraizadas, porcentagem de estacas vivas (com calos e sem raízes, e sem calos e sem raízes), número de raízes por estaca, comprimento das três maiores raízes $(\mathrm{cm})$, porcentagem de folhas retidas, e porcentagem de estacas mortas (mortalidade). No experimento relativo ao final da primavera e final do verão, após a avaliação no período pré-determinado de 90 dias, foi realizada uma segunda avaliação após 60 dias (contabilizando cerca de 150 dias) no caso da primavera e mais 150 dias no caso do verão (contabilizando cerca 240 dias). Tais avaliações foram consideradas como definitivas, sendo adicionada à lista de parâmetros avaliados a média da massa seca das raízes por estaca $(\mathrm{mg})$.

$O$ delineamento experimental utilizado foi inteiramente casualizado, com quatro repetições, quatro tratamentos e 16 estacas por unidade experimental. Para testar a homogeneidade das variâncias utilizou-se o teste de Bartlett e para a verificação da significância da diferença entre as médias, os dados foram submetidos ao teste Tukey a $5 \%$ de probabilidade. Para a realização da análise estatística foi utilizado o programaASSISTAT, versão 7.5 beta (Silva \& Azevedo, 2006).

\section{RESULTADO E DISCUSSÃO}

As estacas coletadas no final da primavera de 2007, bem como, as estacas do final do verão de 2008 foram as únicas que apresentaram enraizamento. Conforme pode ser observado na Tabela 1, a porcentagem média de enraizamento de estacas no final da primavera, decorridos 150 dias da instalação do experimento, foi de 32,1\%. Não houve diferença estatística significativa entre o tratamento testemunha $(39,1 \%)$ e o tratamentos com $2000 \mathrm{mg}$ $\mathrm{L}^{-1}$ de $\mathrm{AIB}(40,6 \%)$, que foram superiores aos tratamentos com 1000 e $3000 \mathrm{mg} \mathrm{L}^{-1}$ (29,7 e 18,8\%, respectivamente).

Entretanto, outros estudos indicam a aparente ausência de correlação entre as concentrações de AIB aplicadas e a porcentagem de enraizamento. Inoue \& Putton (2007), trabalhando com espécies florestais, dentre elas Casearia decandra, observaram nas testemunhas taxas de enraizamento superiores às de estacas tratadas com AIB. Igualmente, Trevisan et al. (2008), com estacas herbáceas de mirtilo, verificaram que não houve efeito significativo do AIB na formação de raízes em estacas coletadas em fevereiro. Isso pode ser explicado, em parte, pelo material estar em pleno desenvolvimento, com balanço hormonal interno favorável ao enraizamento, portanto, com resposta negativa às aplicações de reguladores vegetais sintéticos. Supõese que os níveis de auxina presente nas estacas herbáceas já eram suficientes para a formação das raízes (Trevisan et al., 2008). Dois trabalhos realizados com guaçatonga reportam não existir diferença significativa de enraizamento entre os tratamentos com AIB e os tratamentos sem AIB (Imatomi, 2007; Cavallari, 2008). Imatomi (2007) coletou em duas estações do ano, inverno e verão, estacas lenhosas caulinares retiradas da base de árvores adultas de guaçatonga, com $14 \mathrm{~cm}$ de comprimento e de 2,3 a $3,5 \mathrm{~cm}$ de diâmetro. Os tratamentos comprenderam ferimento lateral e imersão por $24 \mathrm{~h}$ em água e soluções de AIB com e sem boro, assim como imersão rápida (5 segundos ) de estacas sem ferimento em misturas de ANA+AIB. Estacas coletadas no verão tratadas com ANA+AIB $(500 \mathrm{mg}$ $\left.\mathrm{L}^{-1}+1000 \mathrm{mg} \mathrm{L}^{-1}\right)$ em imersão rápida apresentaram a maior porcentagem de enraizamento $(25 \%)$.

Por sua vez, Cavallari (2008), selecionou de árvores adultas de guaçatonga, estacas apicais e medianas, com 7 a $12 \mathrm{~cm}$ de comprimento, coletadas

TABELA 1. Porcentagem de estacas enraizadas, de estacas vivas (com calos e sem raízes e sem calos e sem raízes), de mortalidade e de folhas retidas em estacas de guaçatonga tratadas com diferentes concentrações de ácido indolbutírico (AIB), no final da primavera/2007 e avaliadas após 150 dias.

\begin{tabular}{|c|c|c|c|c|c|}
\hline \multirow[b]{2}{*}{$\begin{array}{c}\text { AlB } \\
\left(\mathrm{mg} \mathrm{L}^{-1}\right)\end{array}$} & \multirow[b]{2}{*}{$\begin{array}{l}\text { Enraizadas } \\
\text { (\%) }\end{array}$} & \multicolumn{2}{|c|}{ Estacas vivas } & \multirow[b]{2}{*}{$\begin{array}{l}\text { Mortalidade } \\
\text { (\%) }\end{array}$} & \multirow[b]{2}{*}{$\begin{array}{c}\text { Folhas retidas } \\
\text { (\%) }\end{array}$} \\
\hline & & $\begin{array}{c}\text { Com calos e } \\
\text { sem raízes (\%) }\end{array}$ & $\begin{array}{c}\text { Sem calos e } \\
\text { sem raízes (\%) }\end{array}$ & & \\
\hline 0 & $39,1 a^{1}$ & $15,6 \mathrm{a}$ & $6,3 a$ & $39,1 \mathrm{~b}$ & $52,3 a$ \\
\hline 1000 & $29,7 a b$ & $23,4 \mathrm{a}$ & $4,7 \mathrm{a}$ & $42,2 \mathrm{ab}$ & $47,7 \mathrm{a}$ \\
\hline 2000 & $40,6 a$ & $21,9 a$ & $3,1 \mathrm{a}$ & $34,4 \mathrm{~b}$ & 49,2 a \\
\hline 3000 & $18,8 \mathrm{~b}$ & $17,2 \mathrm{a}$ & $3,1 \mathrm{a}$ & $60,9 a$ & $35,2 \mathrm{a}$ \\
\hline Média & 32,1 & 19,5 & 4,3 & 44,1 & 46,1 \\
\hline
\end{tabular}

${ }_{1}^{1}$ Médias seguidas pela mesma letra não diferem estatisticamente pelo teste Tukey ao nível de $5 \%$ de probabilidade. 
no final da primavera. Os tratamentos consistiram em imersão lenta (24 horas) das estacas em soluções com diferentes concentrações de AIB. Estacas apicais submetidas a concentrações até $90 \mathrm{mg} \mathrm{L}^{-1}$ de AIB forneceram a maior porcentagem de enraizamento $(21,1 \%)$. Em ambos os trabalhos as estacas que apresentaram maior enraizamento foram aquelas coletadas durante a primavera e o verão, que é o período no qual a guaçatonga não está investindo em produção de estruturas sexuais (Lorenzi, 1992). Assim, a alocação de biomassa é voltada para o crescimento das partes vegetativas, podendo proporcionar maior acúmulo de reservas nos tecidos (Taiz \& Zeiger, 2004). Este fato concorda com os resultados obtidos neste trabalho, porém, a porcentagem de enraizamento das estacas caulinares foi superior à porcentagem obtida por Imatomi (2007) (25\%) e Cavallari (2008) (21,1\%). A ausência de diferença estatística significativa, no presente experimento, entre o tratamento sem fitorregulador (testemunha) e os tratamentos com 1000 e $2000 \mathrm{mg}$ $\mathrm{L}^{-1}$ de AIB, leva a pressupor que a aplicação de auxina exógena não influencie no enraizamento das estacas. Pode-se sugerir também que, concentrações elevadas de AIB ( $3000 \mathrm{mg} \mathrm{L}^{-1}$ ) atuem negativamente. Talvez o possível excesso de auxina exógena, adicionada à endógena, possa ter apresentado efeito inibitório na indução radicial como relatado por Paes et al. (2006) em abélia (Abelia x grandiflora Hort. ex. L. H. Bailey), ou porque os efeitos das auxinas exógenas podem variar durante o ano, influenciando positivamente o enraizamento, ou agindo como inibidor, podendo até causar danos à planta (ZuffellatoRibas \& Rodrigues, 2001; Lana et al., 2008).

No período final da primavera de 2007 a porcentagem de estacas vivas com calos foi superior à porcentagem de estacas vivas sem calos, no momento da avaliação (Tabela 1). O elevado número de calos apresentados, transcorridos os primeiros 90 dias após a instalação do experimento no começo de dezembro e a presença de pequenas raízes surgindo a partir destes, justificou a permanência das estacas em câmara de nebulização por mais 60 dias, até as estacas apresentarem melhor desenvolvimento das raízes. Este resultado concorda com as observações feitas por Endres et al. (2007) em Pau-Brasil, onde pelos altos índices de sobrevivência e baixos índices de enraizamento observados sugeriram que as estacas deviam permanecer por mais tempo sob nebulização, a fim de induzir o processo de enraizamento.

Em estacas onde são retidas as folhas, a auxina endógena, produzida nas folhas e nas gemas, move-se naturalmente segundo um gradiente para a parte inferior do caule, aumentando a concentração na base das estacas, junto com os açúcares e outras substâncias nutritivas (Taiz \& Zeiger, 2004). As folhas adultas servem como órgão de assimilação e reserva de carboidratos, os quais são cruciais para o sucesso do enraizamento. A preservação das folhas garante a sobrevivência das estacas, tanto pela síntese de carboidratos pela fotossíntese, como pelo fornecimento de auxinas e outras substâncias denominadas co-fatores de enraizamento, estimulando a atividade de troca e diferenciação celular (Ono \& Rodrigues, 1996; Hartmann et al., 2002).

Mayer \& Pereira (2003), com estacas de umezeiro, observaram que praticamente $100 \%$ das estacas enraizadas apresentavam pelo menos uma folha oriunda do ramo que deu origem à estaca, assim como a ausência de folhas resultou, em praticamente todos os casos, em estacas com calo ou mortas, tal como foi constatado no presente trabalho.

No que se refere ao número de raízes por estaca, comprimento das três maiores raízes e massa seca de raízes por estaca no período final da primavera, não houve diferença estatística significativa entre os tratamentos (Tabela 2).

No verão, a porcentagem mais elevada de estacas com calos foi de $43,8 \%$ no tratamento com $3000 \mathrm{mg} \mathrm{L}^{-1}$ de AIB. No que se refere às estacas sem calos não houve diferença significativa entre os tratamentos sendo $45,7 \%$ o valor médio (Tabela 3 ).

TABELA 2. Número de raízes por estaca, comprimento das três maiores raízes $(\mathrm{cm})$ e massa seca das raízes $(\mathrm{mg})$ de estacas de guaçatonga tratadas com diferentes concentrações de ácido indolbutírico (AIB), no final da primavera/2007, avaliados após 150 dias.

\begin{tabular}{cccc}
\hline $\begin{array}{c}\text { AlB } \\
(\mathbf{m g ~ L}-\mathbf{1})\end{array}$ & $\begin{array}{c}\text { № de raízes } \\
\text { por estaca }\end{array}$ & $\begin{array}{c}\text { Comprimento 3 } \\
\text { maiores raízes }(\mathbf{c m})\end{array}$ & $\begin{array}{c}\text { Massa seca } \\
\text { das raízes }(\mathbf{m g})\end{array}$ \\
\hline 0 & $5,1 \mathrm{a}^{1}$ & $4,9 \mathrm{a}$ & $30 \mathrm{a}$ \\
1000 & $4,6 \mathrm{a}$ & $5,0 \mathrm{a}$ & $60 \mathrm{a}$ \\
2000 & $5,5 \mathrm{a}$ & $4,1 \mathrm{a}$ & $20 \mathrm{a}$ \\
3000 & $2,6 \mathrm{a}$ & $3,4 \mathrm{a}$ & $20 \mathrm{a}$ \\
\hline Média & 5,2 & 4,4 & 30 \\
\hline
\end{tabular}

${ }^{1}$ Médias seguidas pela mesma letra não diferem estatisticamente pelo teste Tukey ao nível de $5 \%$ de probabilidade.

Rev. Bras. PI. Med., Botucatu, v.14, n.3, p.529-536, 2012. 
A elevada taxa de sobrevivência das estacas em casa de vegetação pode estar relacionada a época de coleta do material, final do verão, que é o período no qual a guaçatonga não está investindo em produção de estruturas sexuais, e, conforme citado anteriormente (Lorenzi, 1992), também a alocação de biomassa é voltada para o crescimento das partes vegetativas, podendo proporcionar maior acúmulo de reservas nos tecidos (Taiz \& Zeiger, 2004).

Foi observado decréscimo do número de folhas retidas com o aumento das concentrações de AIB aplicado (Tabela 3). Foi observado que quase todas as estacas apresentavam pelo menos uma folha retida, das duas iniciais. Tais resultados concordam com aqueles observados por Machado et al. (2005) em estacas semilenhosas do porta-enxerto de videira 'VR043-43' (Vitis vinifera $x$ Vitis rotundifolia). A presença das folhas nas estacas constitui fonte de auxinas e outros hormônios, que são necessários para o enraizamento (Hartmann et al., 2002). Fochesato et al. (2006) verificaram que o número de folhas presentes em estacas semilenhosas de louro (Laurus nobilis L.) apresentou grande influência sobre a sobrevivência das mesmas.

As expectativas de que o aumento do tempo disponível para o enraizamento teria algum efeito positivo sobre o processo, não foram confirmadas completamente, pois após aproximadamente 240 dias da instalação o número de estacas que apresentaram enraizamento foi mínimo. Houve diferença significativa entre os tratamentos sendo que o melhor resultado $(6,3 \%)$ correspondeu ao tratamento com $3000 \mathrm{mg} \mathrm{L}^{-1}$ de AIB (Tabela 4).

O tratamento que apresentou maior número de raízes por estaca, maior comprimento das três maiores raízes e maior massa seca foi o de $3000 \mathrm{mg}$ $\mathrm{L}^{-1}$ de AIB (Tabela 5). AIB nesta concentração e época de coleta das estacas promoveram, portanto, a maior emissão de raízes adventícias nas estacas, aumentando o número e o peso das mesmas, proporcionando assim maior massa seca das raízes, bem como o bom desenvolvimento. A melhor resposta das estacas tratadas com a maior concentração de AIB com respeito ao tratamento testemunha poderia também ser devida à melhor condição geral das estacas e à maior retenção foliar das mesmas.

As estacas colhidas no outono e no inverno não emitiram raízes adventícias. No período relativo ao final do outono, a porcentagem média de mortalidade foi elevada $(76,2 \%)$ sendo que as estacas vivas não apresentaram calos e perderam também

TABELA 3. Porcentagem de estacas vivas (com calos e sem raízes e sem calos e sem raízes), mortalidade e porcentagem de folhas retidas em estacas de guaçatonga tratadas com diferentes concentrações de ácido indolbutírico (AIB), no final do verão/2007 e avaliados após 90 dias.

\begin{tabular}{ccccc}
\hline \multirow{2}{*}{$\begin{array}{c}\text { AIB } \\
\left(\mathbf{m g ~ L}^{-1}\right)\end{array}$} & \multicolumn{2}{c}{ Estacas vivas } & Mortalidade \\
\cline { 2 - 4 } & $\begin{array}{c}\text { Com calos e sem } \\
\text { raízes (\%) }\end{array}$ & $\begin{array}{c}\text { Sem calos e sem } \\
\text { raízes (\%) }\end{array}$ & $\begin{array}{c}\text { Folhas retidas } \\
(\%)\end{array}$ \\
\hline 0 & $28,1 \mathrm{~b}^{1}$ & $51,6 \mathrm{a}$ & $20,3 \mathrm{a}$ & $60,9 \mathrm{a}$ \\
1000 & $28,1 \mathrm{~b}$ & $50,0 \mathrm{a}$ & $21,9 \mathrm{a}$ & $57,8 \mathrm{ab}$ \\
2000 & $29,7 \mathrm{~b}$ & $40,6 \mathrm{a}$ & $29,7 \mathrm{a}$ & $56,3 \mathrm{ab}$ \\
3000 & $43,8 \mathrm{a}$ & $40,6 \mathrm{a}$ & $15,6 \mathrm{a}$ & $47,7 \mathrm{~b}$ \\
\hline 1 & 32,4 & 45,7 & 21,9 & 55,7 \\
\hline
\end{tabular}

TABELA 4. Porcentagem de estacas enraizadas, de estacas vivas (com calos e sem raízes, sem calos e sem raízes), \% de mortalidade e de folhas retidas em estacas de guaçatonga, tratadas com diferentes concentrações de ácido indolbutírico (AIB), no final do verão/2007, avaliados após 240 dias.

\begin{tabular}{cccccc}
\hline \multirow{2}{*}{$\begin{array}{c}\text { AlB } \\
\left(\mathbf{m g ~ L}^{-1}\right)\end{array}$} & $\begin{array}{c}\text { Enraizadas } \\
(\%)\end{array}$ & \multicolumn{2}{c}{ Estacas vivas } & $\begin{array}{c}\text { Mortalidade } \\
\text { (\%) }\end{array}$ & $\begin{array}{c}\text { Folhas retidas } \\
\text { (\%) }\end{array}$ \\
\cline { 3 - 4 } & $\begin{array}{c}\text { Com calos e sem } \\
\text { raízes (\%) }\end{array}$ & $\begin{array}{c}\text { Sem calos e sem } \\
\text { raízes (\%) }\end{array}$ & & \\
\hline 0 & $1,6 \mathrm{~b}^{1}$ & $14,0 \mathrm{~b}$ & $31,3 \mathrm{a}$ & $51,6 \mathrm{bc}$ & $5,5 \mathrm{ab}$ \\
1000 & 0 & $6,3 \mathrm{~b}$ & $21,9 \mathrm{a}$ & $71,9 \mathrm{a}$ & $2,4 \mathrm{bc}$ \\
2000 & $3,1 \mathrm{ab}$ & $15,6 \mathrm{ab}$ & $15,6 \mathrm{a}$ & $65,6 \mathrm{ab}$ & $0,9 \mathrm{c}$ \\
3000 & $6,3 \mathrm{a}$ & $25,6 \mathrm{a}$ & $26,6 \mathrm{a}$ & $40,6 \mathrm{c}$ & $9,4 \mathrm{a}$ \\
\hline Média & 2,8 & 15,4 & 23,9 & 57,4 & 4,6 \\
\hline
\end{tabular}

${ }^{1}$ Médias seguidas pela mesma letra não diferem estatisticamente pelo teste Tukey ao nível de $5 \%$ de probabilidade. 
TABELA 5. Número de raízes por estaca, comprimento das três maiores raízes $(\mathrm{cm})$, massa seca das raízes $(\mathrm{mg})$ de estacas de guaçatonga tratadas com diferentes concentrações de ácido indolbutírico (AIB), no final do verão/ 2007, avaliados após 240 dias.

\begin{tabular}{ccccc}
\hline $\begin{array}{c}\text { AlB } \\
(\mathbf{m g ~ L}-1)\end{array}$ & $\begin{array}{c}\text { № de raízes } \\
\text { por estaca }\end{array}$ & $\begin{array}{c}\text { Comprimento 3 } \\
\text { maiores raízes }(\mathbf{c m})\end{array}$ & $\begin{array}{c}\text { Massa seca das } \\
\text { raízes }(\mathbf{m g})\end{array}$ \\
\hline 0 & $0,8 \mathrm{~b}^{1}$ & $1 \mathrm{~b}$ & $16 \mathrm{~b}$ \\
1000 & 0 & 0 & 0 \\
2000 & $0,4 \mathrm{c}$ & $0,2 \mathrm{c}$ & $12 \mathrm{~b}$ \\
3000 & $6,4 \mathrm{a}$ & $3,3 \mathrm{a}$ & $97 \mathrm{a}$ \\
\hline Média & 5,2 & 1,1 & 31,3 \\
\hline
\end{tabular}

${ }^{1}$ Médias seguidas pela mesma letra não diferem estatisticamente pelo teste Tukey ao nível de $5 \%$ de probabilidade.

boa parte das folhas (Tabela 6). As estacas relativas ao tratamento com $3000 \mathrm{mg} \mathrm{L}^{-1}$ de AIB diferiram estatísticamente dos demais tratamentos quanto à porcentagem de estacas vivas (sem calo e sem raízes) e mortalidade, porém, a aplicação do regulador vegetal não teve influência significativa na retenção foliar. Quase a totalidade das estacas coletadas no final do inverno morreu, não havendo diferenças estatísticas significativas entre os tratamentos (Tabela 6). Estacas tratadas com $2000 \mathrm{mg} \mathrm{L}^{-1}$ de AIB apresentaram maiores percentuais de estacas vivas e de folhas, no entanto, com valores muito modestos (Tabela 6).

Mindêllo Neto (2006), em estacas herbáceas de pessegueiro (Prunus persica), relatou enraizamento nulo ou insignificante quando as estacas estavam desprovidas de folhas. Nos dois períodos não foram observados calos nas estacas vivas no momento da avaliação, resultado que também concordou com o obtido por Endres et al. (2007) onde a formação de calos não foi relacionada com a concentração de auxina utilizada indicando que o alto índice de sobrevivência das estacas aparentemente não garante que as estacas estejam em processo de diferenciação, ou seja, ocorrendo a formação de calos ou rizogênese.
Segundo Neves et al. (2006), no outono os dias curtos e as temperaturas baixas do ambiente exercem influência negativa no processo fotossintético das árvores matrizes. No inverno, dias curtos e baixas temperaturas alteram processos fisiológicos, como a fotossíntese e translocação de compostos, das árvores matrizes, o que pode dificultar o enraizamento das estacas obtidas. A porcentagem de enraizamento diminui com a proximidade do inverno, quando os níveis de ácido abscísico (ABA) são normalmente altos. Tais fatores provavelmente influenciaram o comportamento das estacas de guaçatonga coletadas no presente trabalho.

A guaçatonga, segundo Forster \& Melo (2007), possui ritmo de crescimento médio, o que parece justificar os tempos prolongados de permanência em casa de vegetação, pois foram necessários cerca de 150 dias para obter o desenvolvimento das raízes. A estação de coleta está estreitamente relacionada com a consistência da estaca e estacas coletadas no período de crescimento vegetativo intenso (primavera/verão) apresentam-se mais herbáceas e, de modo geral, espécies difíceis de enraizar como a guaçatonga (Imatomi, 2007; Cavallari, 2008), mostram maior

TABELA 6. Porcentagem de estacas sem calos e sem raízes, de folhas retidas e de mortalidade em estacas de guaçatonga tratadas com diferentes concentrações de ácido indolbutírico (AIB) no final do outono/2007 e no final do inverno/2007, avaliadas após 90 días.

\begin{tabular}{|c|c|c|c|c|c|c|}
\hline \multirow{2}{*}{$\begin{array}{c}\text { AlB } \\
\left(\mathrm{mg} \mathrm{L}^{-1}\right)\end{array}$} & \multicolumn{3}{|c|}{ Outono } & \multicolumn{3}{|c|}{ Inverno } \\
\hline & $\begin{array}{c}\text { S/calos e s/ } \\
\text { raízes (\%) }\end{array}$ & $\begin{array}{c}\text { Folhas } \\
\text { retidas (\%) }\end{array}$ & $\begin{array}{c}\text { Mortalidade } \\
\text { (\%) }\end{array}$ & $\begin{array}{c}\text { S/calos e s/ } \\
\text { raízes (\%) }\end{array}$ & $\begin{array}{c}\text { Folhas } \\
\text { retidas (\%) }\end{array}$ & $\begin{array}{c}\text { Mortalidade } \\
\text { (\%) }\end{array}$ \\
\hline 0 & $15,6 b^{1}$ & $14,0 \mathrm{a}$ & 84,4 a & $6,3 \mathrm{~b}$ & $3,9 \mathrm{c}$ & 93,7 a \\
\hline 1000 & $21,9 b$ & $16,4 \mathrm{a}$ & $78,1 \mathrm{a}$ & 0 & 0 & $100,0 \mathrm{a}$ \\
\hline 2000 & $14,1 \mathrm{~b}$ & $10,9 a$ & 85,9 a & $14,1 \mathrm{a}$ & $10,9 a$ & $85,9 a$ \\
\hline 3000 & $43,7 \mathrm{a}$ & $14,0 \mathrm{a}$ & $56,3 \mathrm{~b}$ & $6,3 \mathrm{~b}$ & $6,2 \mathrm{~b}$ & 93,7 a \\
\hline Média & 23,4 & 13,8 & 76,2 & 6,7 & 5,3 & 93,4 \\
\hline
\end{tabular}

${ }^{1}$ Médias seguidas pela mesma letra não diferem estatisticamente teste Tukey ao nível de $5 \%$ de probabilidade. 
capacidade de enraizamento, enquanto estacas coletadas no inverno possuem maior grau de lignificação e tendem a enraizar menos (Fachinello et al., 1995).

Em nenhuma das épocas avaliadas foram emitidas brotações nas estacas. A ausência de brotações é um resultado negativo que pressupõe a continuação das pesquisas.

Conclui-se, portanto, que a guaçatonga pode ser considerada uma espécie de difícil enraizamento. Para a rizogênese em estaca caulinar semilenhosa de guaçatonga a melhor época de coleta é o final da primavera e as concentrações de AIB testadas (nas condições deste trabalho) não têm efeito sobre o enraizamento das estacas. Para favorecer o aumento da porcentagem de enraizamento e a produção de brotações são ainda necessários ulteriores estudos, para avaliar outros fatores, como o tipo de estaca, utilizando material rejuvenescido originário de brotações das plantas matrizes e o uso de diferentes tipos de reguladores vegetais, tendo em vista que, com a simples modificação em uma ou mais condições, pode-se viabilizar a propagação vegetativa de espécies consideradas de difícil enraizamento, como a guaçatonga.

\section{AGRADECIMENTO}

Ao Programa de Desenvolvimento Tecnológico Avançado (PDTA) da Fundação Parque Tecnológico de ITAIPU (FPTI) pelo apoio financeiro para o desenvolvimento do presente trabalho.

\section{REFERÊNCIA}

APG II: An update of the angiosperm phylogeny group classification for the orders and families of flowering plants. Botanical Journal of the Linnean Society, v.141, p.399-436, 2003.

BORGES, M.H. et al. Effects of aqueous extract of Casearia sylvestris (Flacourtiaceae) on actions of snake and bee venoms and on activity of phospholipases A2. Comparative Biochemistry and Physiology, part B: Biochemistry and Molecular Biology, v.127, n.1, p.2130, 2000.

BORGES, M.H et al. Neutralization of proteases from Bothrops snake venoms by the aqueous extract from Casearia sylvestris (Flacourtiaceae). Toxicon, v.39, n.12, p.1863-9, 2001.

CAVALLARI, M.M. Variabilidade genética e química entre e dentro de populações de Casearia sylvestris Sw. (Salicaceae) no Estado de São Paulo. 2008. 127p. Tese (Doutorado - Área de Concentração em Genética Vegetal) - Instituto de Biociências, Universidade Estadual Paulista, Botucatu.

DURIGAN, G. et al. The vegetation of priority areas for cerrado conservation in São Paulo State, Brazil. Edinburgh Journal of Botany, v.60, p.217-41, 2003.
ENDRES, L. et al. Enraizamento de estacas de PauBrasil (Caesalpinia echinata Lam.) tratadas com ácido indol butírico e ácido naftaleno acético. Ciência Rural, v.37, n.3, p.886-9, 2007.

ESTEVES, I. et al. Gastric antiulcer and anti-inflammatory activities of the essential oil from Casearia sylvestris Sw. Journal of Ethnopharmacology, v.101, n.1, p.191-6, 2005. FACHINELLO, J.C.; HOFFMANN, A.; NACHTIGAL, J.C. Propagação de plantas frutíferas de clima temperado. 2.ed. Pelotas: Editora Universitária, 1995. 178p.

FOCHESATO, M.L. et al. Propagação de louro (Laurus nobilis L.) por estacas semilenhosas com diferentes quantidades de folhas e tratadas com ácido indolbutírico. Revista Brasileira de Plantas Medicinais, v.8, n.3, p.72-7, 2006.

FORSTER, H.F.; MELO, A.C.G. Biomassa aérea e de raízes em árvores de reflorestamentos heterogêneos no Vale do Paranapanema, SP. IF Série Registros, n.31, p.153-7, 2007.

HARTMANN, H.T. et al. Plant propagation: principles and practices. 7.ed. Upper Saddle River: Prentice Hall, 2002. $880 \mathrm{p}$.

IMATOMI, M. Interferência de fatores bióticos e abióticos na propagação e conservação de Casearia sylvestris Swartz (Salicaceae). 2007. 103p. Dissertação (Mestrado - Área de Concentração em Ecologia e Recursos Naturais) - Centro de Ciências Biológicas e da Saúde, Universidade Federal de São Carlos, São Carlos.

INOUE, M.T.; PUTTON, V. Macropropagação de 12 espécies arbóreas da Floresta ombrófila mista. Floresta, v.37, n.1, 55-61, 2007.

JOLY, A.B. Botânica: Introdução à taxonomia vegetal, 12.ed. São Paulo: Companhia Editora Nacional, 1998. $777 p$.

LANA, R.M.Q. et al. Doses do ácido indolbutírico no enraizamento e crescimento de estacas de eucalipto (Eucalyptus urophylla). Bioscience Journal, v.24, n.3, p.13-8, 2008.

LORENZI, H. Árvores brasileiras. Nova Odessa: Plantarum, 1992. 115p.

MACHADO, M.P. et al. Ácido indolbutírico no enraizamento de estacas semilenhosas do porta-enxerto de videira 'VR043-43' (Vitis vinifera x Vitis rotundifolia). Revista Brasileira de Fruticultura, v.27, n.3, p.476-9, 2005.

MARQUETE, R.; VAZ, A.M.S.F. O gênero Casearia no estado do Rio de Janeiro. Rodriguésia, n.58, v.4, p.70538, 2007.

MAYER, N.A.; PEREIRA, F.M. Enraizamento de estacas herbáceas de quatro clones de umezeiro (Prunus mume Sieb. et Zucc.) durante o inverno ameno, em JaboticabalSP. Revista Brasileira de Fruticultura, v.25, n.3, p.505-7, 2003.

MINDÊLLO NETO, U. Estaquia herbácea de pessegueiro cv. Charme, em função de diferentes concentrações de ácido indolbutírico (AIB) e número de folhas. Revista Brasileira de Agrociência, v.12, n.1, p.27-9, 2006. NEVES, T.S. et al. Enraizamento de corticeira-da-serra em função do tipo de estaca e variações sazonais. Pesquisa Agropecuaria Brasileira, v.41, n.12, p.1699705, 2006

ONO, E.O.; RODRIGUES, J.D. Aspectos da fisiologia do enraizamento de estacas caulinares. Jaboticabal: FUNEP, 1996. 83p. 
PAES, E.G.B. et al. Estaquia de Abelia x grandiflora Hort. ex L. H. Bailey. Cultura Agronômica, v.15, n.1, p.26-36, 2006.

PEREIRA, V.A.M.; PARON, M.E.; MING, L.C. Enraizamento de estacas de Casearia sylvestris Swartz. In: JORNADA PAULISTADE PLANTAS MEDICINAIS, 6., 2003, São Pedro. Resumos... São Paulo: FCFAr/IQ/Unesp, 2003. Disponível em: <http://www.fcfar. unesp.br/jppm/cd/pdf_fitotecnia/ V.A.M.Pereira.pdf>. Acesso em: 20 out. 2010.

RUPPELT, B.M. et al. Pharmacological screening of plants recommended by folk medicine as anti-snake venom-I. Analgesic and anti-inflammatory activities. Memorias do Instituto Oswaldo Cruz, v.86, p.203-5, 1991.

SILVA, F.A.S.E.; AZEVEDO, C.A.V. A new version of the assistat-statistical assistance software. In: WORLD CONGRESS ON COMPUTERS IN AGRICULTURE, 4., 2006, Orlando. Proceedings... Orlando: American Society of Agricultural and Biological Engineers, 2006. p.393-6.

SILVA, M.A.S. Variabilidade genética e fitoquímica de Casearia sylvestris Sw. em populações do cerrado e mata atlântica do Estado de São Paulo. 2003. 127p.

Tese (Doutorado - Área de Concentração em Agronomia e Horticultura) - Faculdade de Ciências Agronômicas, Universidade Estadual Paulista, Botucatu.

SILVA, S.L. et al. Cytotoxic evaluation of essential oil from Casearia sylvestris Sw. on human cancer cells and erythrocytes. Acta Amazonica, v.38, n.1, p.10-2, 2008.

SLEUMER, H.O. Flora Neotropica: Monograph n.22 (Flacourtiaceae). New York: The New York Botanical Garden, 1980. 499p.

TAIZ, L.; ZEIGER. L. Fisiologia vegetal. 3.ed. Porto Alegre: Artmed, 2004. 719p.

TAYLOR, L. Herbal secrets of the rainforest. 2.ed. Austin: Sage Press, 2002. 360p.

TORRES, R.B.; YAMAMOTO, K. Taxonomia das espécies de Casearia Jacq. (Flacourtiaceae) do estado de São Paulo. Revista Brasileira de Botânica, v.9, p.239-58, 1986.

TREVISAN, R. et al. Enraizamento de estacas herbáceas de mirtilo: influência da lesão na base e do ácido indolbutírico. Ciência agrotécnica, v.32, n.2, p.402-6, 2008.

ZUFFELLATO-RIBAS, K.C.; RODRIGUES, J.D. Estaquia: uma abordagem dos principais aspectos fisiológicos. Curitiba: [K.C. Zuffellato-Ribas], 2001. 39p. 